American Journal of Applied Sciences 7 (5): 647-655, 2010

ISSN 1546-9239

(C) 2010Science Publications

\title{
Estimate of Aerosol Optical Depth Using Broadband Direct Normal Observations at Highest Polluted Area in the World
}

\author{
${ }^{1}$ U. Ali Rahoma and ${ }^{2}$ A.H. Hassan \\ ${ }^{1}$ Department of Medical Radiology, Faculty of Medical Technology, \\ ${ }^{2}$ Department of Physics, Faculty of Education, \\ Omer El-Mukhtar University, Tobruk, Libya
}

\begin{abstract}
Problem statement: The measurement of different components of direct solar radiation for this research has been carried out in Helwan, Egypt. Helwan (Latitude $29^{\circ} 52 \mathrm{~N}$, Longitude $31^{\circ} 20 \mathrm{E}$ ). This is a considered as the largest polluted region in the world. The level of pollution in Helwan region is higher, compared to the international limit by about 7 or 10 times in industrial and populated region respectively. Approach: The daily variation for different components of solar radiation bands as global, direct (total, yellow, red and infrared) and diffuse solar radiation had been studied and discussed. The data measurements have been taken for nine years (1991-2000). Hourly data of solar irradiance on a horizontal plane had also been recorded simultaneously together with relative humidity and wind speed along with some traditional techniques for selecting the clear sky days of the period examined. Results: The results clearly showed seasonal dynamics in aerosol loading, type and perceptible water. Conclusion: Background levels of aerosols, which we defined as yellow color less than 0.10 , had observed at almost all sites but varying frequencies.
\end{abstract}

Key words: Optical density, aerosols, solar radiation spectrum, climate change, statistical moments

\section{INTRODUCTION}

Man is altering the aerosol environment through land cover change, combustion of fossil fuels and the introduction of particulate and gas species to the atmosphere. Each perturbation has some impact on the local aerosol environment. How much aerosol man is contributing to the atmosphere has not known? Fundamentally, we do not know the current total aerosol loading, thus, we have no definitive measure of change for future assessment (Andreae, 1996). Regardless of current conditions, the extent of local aerosol perturbations on a global scale is the subject of extensive ground level, airborne and satellite research (King et al., 1999; Pruppacher and Klett, 1978). The inter-governmental panel on climate change lists aerosols as one of the most important anthropogenic radioactive agents that tend to decrease temperature (Intergovernmental Panel on Climate Change, 1994). West Africa and desert dust aerosol has been the focus of three network sun photometric investigations for much of the 1980's. The African turbidity network from 19801984 (D'Almeida, 1996), NASA's 15 site Sahelian network (Eck et al., 1999) and the Niger network from 1986-1987 (Ben Mohamed et al., 1992) clearly, demonstrated the temporal and spatial variability and overall high aerosol loading in West Africa, during this decade of extreme Sahelian drought.

Aerosol optical depth has been retrieved using broadband $(0.3-4 \mu \mathrm{m})$ direct normal observations made from pyrheliometers, which have more commonly deployed at meteorological observatories. Effective optical depth retrievals have made at $750 \mathrm{~nm}$ with an estimated accuracy of $10 \%$ due to the retrieval method but no mention is made of errors due to calibration uncertainty. High optical depths, for the colder interior cities in winter due to emissions from coal heating and springtime pulses from dust sources, have routinely reported. In contrast, Beijing reported a summer maximum. None of these sites necessarily represents rural conditions (Jinhuan and Liquan, 2000). Broad band aerosol optical depths from pyrheliometers $(0.3-3 \mu \mathrm{m})$ as monthly average anomalies from measurements taken for four NOAA/CMDL background stations (Barrow, AK, Mauna Loa, HI, Samoa, US. Territories and South Pole) from 1977-1992 (Dutton et al., 1994).

\section{MATERIALS AND METHODS}

Data description: The daily distribution of solar radiation has known to vary considerably due to the

Corresponding Author: U. Ali Rahoma, Department of Medical Radiology, Faculty of Medical Technology, Omer El-Mukhtar University, Tobruk, Libya Tel: +218-92-5358557 Fax: 002-02-5548020 
influence of the changing astronomy and environmental factors. Measurements of the different components of Global (G), total direct (I), direct Yellow (Y), direct Red (R), direct Infrared (IR) and calculate the Diffuse solar radiation (D) from the equation:

$$
\mathrm{D}=\mathrm{G}-\mathrm{I} \operatorname{COS}(\mathrm{z})
$$

where, $\mathrm{z}$ is the zenith angle, besides the meteorological and environmental parameters, air Temperature (T), Relative Humidity (RH) and Visibility (V) as a function in the air pollution. The sources of pollution are cement, engineering, iron and steel factories. The data measurement has carried out from Sunrise (SR) to Sunset (SS) through 9 year (1991-1999). The statistical weight number for the data average is 40 day month ${ }^{-1}$.

The equipment has installed on the top roof of the building of NRIAG. The solar radiation station including normal incidence Pyrheliometer using three colors filter bands OG530 (530-2800 nm), RG630 $(630-2800 \mathrm{~nm})$ and RG695 $(695-2800 \mathrm{~nm})$ are used, the precision spectral pyranometer measured from 280-2800 nm (made in EBLAB (USA)). The bands under study are classified into five bands for direct solar radiation, B1 $(280-2800 \mathrm{~nm}), \quad$ B2 $\quad(280-$ $530 \mathrm{~nm}), \mathrm{B} 3(530-630 \mathrm{~nm}), \mathrm{B} 4(630-695 \mathrm{~nm})$ and B5 $(695-2800 \mathrm{~nm})$.

State of air quality in Helwan: The major sources of pollution at Helwan are due to three types of factors such as:

- Cement factories, which include 4 factories distributed from the north in Tura to the south in EL-Tebeen

- Engineering industries (Cars, pipes and tubes factories)

- Iron and steel factories

The major source of the wind directions are from the $\mathrm{N}$ and $\mathrm{N}-\mathrm{E}$, which represents about $50 \%$ of the total direction. This means that the Tura EL-Cement and Helwan Portland cement factories represent $50 \%$ of the pollution of Helwan region. The national cement factory and iron steel factories represent about $40 \%(\mathrm{~N}-$ $\mathrm{W}, \mathrm{S}, \mathrm{W}, \mathrm{S}-\mathrm{W}$ directions) of the total pollution at Helwan region. Also EL-Tebeen (S-W from Helwan) is considered a very high polluted region because of all cement factories besides $50 \%$ from the iron and steel factory pour out in this region (Mosalam Shaltout and Rahoma, 1996). Table 1 represents the amount of suspended particulate, international limit and the increase percentage in industrial cities. The concentration of suspended particles are such as

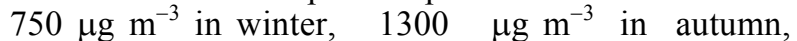
$1500 \mu \mathrm{g} \mathrm{m}^{-3}$ in spring and $1600 \mu \mathrm{g} \mathrm{m}^{-3}$ in summer (Mosalam Shaltout et al., 1998). The Table 2 represents the limit of carbon monoxide in different units and the increase percentage in the iron and steel factory as a comparison between the universal limits and the different furnaces at Helwan factories. Inspection of these two tables, leads to the amount of pollutant that has increased from 145 ton mile ${ }^{-2}$ month $^{-1}$ in 1967 to more than 500 ton mile month $^{-1}$ in 1988. The accepted limit, however are 20 ton mile ${ }^{-2}$ month $^{-1}$ in the urban and commercial region and 40 ton mile ${ }^{-2}$ month $^{-1}$ in the industrial region in the world (Mosalam Shaltout et al., 2001). This means that the level of pollution in Helwan region has higher, compared to the international limit by about $1250-2500 \%$ in industrial and populated regions, while the percentage increase for the carbon monoxide level is $250-1000 \%$. Elements that exists in Helwan atmosphere with relatively high abundance are in descending order like Calcium $(\mathrm{Ca})$, Iron $(\mathrm{Fe})$, Manganese (Mn), Lead (Plumbum) (Pb), Phosphorus (P) and Zinc (Zn) (Mattar and Rahoma, 2002).

The pollution reduced the UV direct solar radiation $(\lambda<375 \mathrm{~nm})$ by $50 \%$ due to cement exhaust in atmosphere (Trabeaa and Shaltout, 2000; Elminir et al., 2004). This study revealed a decrease of direct radiation by $30-45 \%$ with respect to the results of 1922 and by $20 \%$ with respect to 1967 (Mosalam Shaltout and Rahoma, 1996). The environmental pollutants and their effects on the photovoltaic performance in the desert climate of Egypt have demonstrated that, the pollutants reduced the direct radiation by $43 \%$, global radiation by $19 \%$ and increase the diffuse radiation by $72 \%$ (Hassan, 2001).

Table 1: Concentration of suspended particles at different seasons in Helwan area $\left(\mu \mathrm{g} \mathrm{m}^{-3}\right)$ (Mosalam Shaltout et al., 1998)

\begin{tabular}{lrrrr} 
& \multicolumn{2}{c}{ Measured values } & \multicolumn{2}{c}{ Allowed values } \\
& \multicolumn{1}{c}{ Min } & Max & Min & Max \\
Season & 400 & 815 & 70 & 90 \\
\hline Spring & 1250 & 1614 & 120 & 150 \\
Summer & 820 & 1212 & 60 & 81 \\
Autumn & 250 & 400 & 50 & 70 \\
Winter & & & & \\
\hline
\end{tabular}

Table 2: Monthly variation of dust fall ( $\mathrm{mg} \mathrm{m}^{-2} \mathrm{month}$ ) for five sites in Helwan area (Mattar and Rahoma, 2002)

\begin{tabular}{llllllrrrrrrrr}
\hline Site & J & F & M & \multicolumn{1}{c}{ A } & \multicolumn{1}{c}{ M } & \multicolumn{1}{c}{ J } & J & A & S & O & N & D & Mean \\
\hline 1 & 252 & 215 & 183 & 147 & 320 & 138 & 68 & 75 & 42 & 47.0 & 50 & 53 & 132.5 \\
2 & 103 & 307 & 236 & 94 & 112 & 38 & 47 & 82 & 48 & 50.7 & 40 & 50 & 100.6 \\
3 & 378 & 430 & 779 & 813 & 2023 & 1035 & 129 & 160 & 974 & 1680.0 & 2297 & 877 & 964.9 \\
4 & 327 & 311 & 422 & 204 & 1222 & 243 & 236 & 116 & 178 & 269.0 & 189 & 287 & 333.7 \\
5 & 21 & 43 & 31 & 55 & 94 & 13 & 23 & 25 & 36 & 12.0 & 19 & 26 & 33.17 \\
\hline
\end{tabular}


The pollutants are reduced the clearness index by $12 \%$ and increase the diffuse fraction by $91 \%$. The spectral composition of the global solar radiation has found to be; $3.3 \% \mathrm{UV}, 32.2 \%(530-630 \mathrm{~nm})$, $12.79 \%(630-695 \mathrm{~nm}), 51.7 \%(695-2800 \mathrm{~nm})$ and $29.7 \%$ for diffuse solar radiation. The wide distribution of the energetic band of different components of direct solar radiation (I, Y, R and IR) are largely wide from global, where the range of the energetic band of total direct (I) is 8-12 band width, while for $\mathrm{G}$ it is 3-8 band width. This means that the large type of pollution (from large size to small size) absorbs a different spectrum of wavelength (from short to long wavelength) (Rahoma, 2001; 2004).

Determination of the different atmospheric turbidity parameter: The bases for the calculations of the spectral aerosol optical depth OD are the spectral solar irradiance measurements and the Bouguer-Lambert law, the solar flux between wavelength $\lambda_{1}$ and $\lambda_{2}$ can been expressed as:

$\mathrm{I}(\lambda)=\mathrm{I}\left(\lambda_{1}, \lambda_{2}\right)=(1 / \mathrm{S}) \int_{\lambda_{1}}^{\lambda_{2}} \mathrm{I}_{0}(\lambda) \cdot \mathrm{e}^{-\mathrm{a}(\lambda) \cdot \mathrm{m}} \mathrm{d} \lambda$

$\mathrm{I}\left(\lambda_{1}, \lambda_{2}\right)=$ The direct solar flux at earth's surface,

$\mathrm{I}_{0}(\lambda)=$ The spectral irradiance at the top of the atmosphere,

$\mathrm{a}(\lambda)=$ The global extinction coefficient at wavelength $\lambda$

$\mathrm{S} \quad=$ The correction factor for earth-sun distance.

$\mathrm{a}(\lambda) \quad=$ Can be expressed as:

$\mathrm{ma}(\lambda)=\mathrm{ma}_{\mathrm{r}}(\lambda)+\mathrm{m}_{\mathrm{r}} \mathrm{a}_{\mathrm{d}}(\lambda)+\mathrm{m}_{\mathrm{r}} \mathrm{a}_{\mathrm{w}}(\lambda)$

$\mathrm{m}_{\mathrm{r}}=\left(\frac{\mathrm{P}}{1013.25}\right) \frac{1}{\cos \theta_{\mathrm{z}}+0.15\left(93.885-\theta_{\mathrm{z}}\right)^{-1.253}}$

Where:

$\mathrm{m}=$ The absolute air mass, (Sonntag, 1989)

$\mathrm{m}_{\mathrm{r}} \quad=$ The relative air mass

$\mathrm{a}_{\mathrm{r}}(\lambda)=$ The Rayleigh extinction coefficient per unit absolute air mass

$\mathrm{a}_{\mathrm{w}}(\lambda)=$ The selective absorption coefficient for the atmospheric gases $\mathrm{O}_{2}, \mathrm{O}_{3}, \mathrm{H}_{2} \mathrm{O}, \mathrm{CO}_{2}$

$\mathrm{a}_{\mathrm{d}}(\lambda)=$ The aerosol extinction coefficient. The total spectral of OD calculated as:

$\mathrm{OD}=-\frac{1}{\mathrm{~m}} \ln \frac{\mathrm{I}(\lambda)}{\mathrm{I}_{0}(\lambda)}$
To take account of the scattering by air molecules, the following equation has used as recommended by the WMO (Forgan et al., 1993):

$\mathrm{a}_{\mathrm{r}}(\lambda)=\frac{\mathrm{P}}{1013.25} 0.00865 \lambda^{-(3.916+0.074 \lambda+0.05 / \lambda)}$

Where:

$\lambda=$ The wavelength in $\mu \mathrm{m}$

$\mathrm{P}=$ The pressure in $\mathrm{hPa}$

The amount of the ozone absorption (Chappuis bands) has evaluated through the direct determination of the total ozone concentration using Dobson and Brewer spectrometer measurements from Helwan station, the amount of lower surface ozone layer, ranged 21-80 $\mathrm{\mu g} \mathrm{m}^{-3}$ (Elminir et al., 2004). These levels can be neglected, since these amounts $\left(\mathrm{a}_{\mathrm{w}}(\lambda) \approx 0.0009\right)$ are considerably smaller than the precision of a single measurement. $\mathrm{NO}_{2}$ concentration are low (0.6-3DU) and exhibit little regional variations and thus are almost negligible with respect to the aerosol concentration when considering the precision of the algorithmic retrieval method used in inferring the aerosol parameters, with the exception of data measured at Helwan.

Different turbidity parameters:

Angstrom turbidity: According to Angstrom (1996), $a_{d}(\lambda)$ can be expressed by the formula:

$\mathrm{a}_{\mathrm{d}}(\lambda)=\beta_{0} \lambda^{-\alpha}$

Where:

$\beta_{0}=$ The turbidity coefficient, characterizing the aerosol content

$\alpha=$ The Wavelength of the exponent, closely related to the size distribution of particles $\alpha$ varies between 0 and 4

The values $\alpha=1.3$ suggested by Angstrom (1996) is currently accepted.

Schuepp turbidity coefficients: For a given wavelength band $\Delta \lambda$, Schuepp (1949) defines a turbidity coefficient, $\mathrm{B}_{\Delta \lambda}$ by $\mathrm{a}_{\mathrm{r}}$ and $\mathrm{a}_{\mathrm{w}}$ relation:

$\mathrm{B}_{\Delta \lambda}=\frac{\log \frac{1}{\mathrm{~s}} \frac{\mathrm{I}_{0}(\Delta \lambda)}{\mathrm{I}(\Delta \lambda)}}{\mathrm{m}}-\left(\mathrm{a}_{\mathrm{r}}+\mathrm{a}_{\mathrm{w}}\right)$

And $B_{\Delta \lambda}$ is related to $\beta_{0}$ and $\alpha$ by the formula: 
Am. J. Applied Sci., 7 (5): 647-655, 2010

$\mathrm{B}_{\Delta \lambda}=\beta_{0} \bar{\lambda}^{-\alpha} \log \mathrm{e}$

$\bar{\lambda}$ being is the effective mean wavelength in the band $\Delta \lambda$.

Linke factor (turbidity): The Link factor has expressed as (Katez et al., 1982):

$\mathrm{T}=\frac{\mathrm{a}(\lambda)}{\mathrm{a}_{\mathrm{r}}}$

Wavelength exponent: Knowing two turbidity coefficients $B_{i}$ and $B_{j}, \alpha_{i j}$ is calculated as follows:

$$
\alpha_{i j}=\frac{\log \frac{B_{i}}{B_{j}}}{\log \frac{\lambda_{j}}{\lambda_{i}}}
$$

Theoretically, many values of $\alpha$ can be derived from different $\mathrm{B}$ coefficients. However, due to the extreme sensitivity of $\alpha$ to experimental errors, only $\alpha$ value based on measurements in the bands 3-4 are used (see recommendations of the WMO Technical report (Katez et al., 1982).

\section{RESULTS}

The results of the measurements and analysis: The general climate of Helwan dry, hot and desert type, the Nile and adjacent narrow cultivation belts have very limited local modifications on the climate. This meansmonthly cloud's amount does not exceed 0.4 Oktas. The cloudiness is greater in Helwan reaches its maximum in winter while it's minimum value his attained in summer. This formation is due to radiation less and turbulence in the humid, surface layer and usually disperses within two to $4 \mathrm{~h}$ after sunrise, leaving generally, a clear sky until the following morning. The change from the Mediterranean depressions of the winter to the Khamasien depression of spring causes rather a sudden rise in temperature. The sudden change from the summer time regime to the winter one, often occurring in late October, causes a very drastic alteration in mean monthly temperature. The highest values of the maximum temperature occur in July and August. The maximum temperature reached $40^{\circ} \mathrm{C}$ in most places, the lowest temperature are encountered in winter in the heart of the western desert, between $25^{\circ}$ and $29^{\circ} \mathrm{N}$ and west of $31^{\circ} \mathrm{E}$. The intensive natural variation, under high pressure, is due to clear skies, dry air and a sandy soil. The highest values occur in spring with the alternating hot and cold spells while the lowest values occur in the settled summer months. A detailed discussion of the monthly of the Aerosol Optical Depth (AOD); at different bands B1-B5 corresponding by standard deviation of all bands as shown in Table 3a. From the present an analysis of aerosol optical depth data at Helwan, it is noted that the higher distributed values of AOD are $0.61,0.51,0.69,0.48,0.68$ at June and minimum is $0.38,0.37,0.40,0.32,0.35$ at January corresponding to $\mathrm{B} 1, \ldots, \mathrm{B} 5$. Highly values of $\mathrm{SD}$ for $\mathrm{AOD}$ in the $\mathrm{B} 5$ and minimum at $\mathrm{B} 2$. SD has ranged from $0.04-0.11$. The mean values for AOD indicated to the values of $\mathrm{B} 3$ are 0.55 and $\mathrm{B} 5$ is 0.54 and $\mathrm{B} 1$ is 0.50 and $\mathrm{B} 2$ is 0.44 and $\mathrm{B} 4$ is 0.40 . This means-the higher values ranged in the band $\mathrm{B} 3(530-630 \mathrm{~nm})$. A detailed discussion for the monthly of the Schuepp Turbidity coefficient (ST) at different bands B1, B2, B3, B4 and B5 corresponding by the standard deviation of all bands as shown in Table $3 \mathrm{~b}$. From Table $3 \mathrm{~b}$ and the previous discussion for the AOD, the higher values of $\mathrm{ST}$ at $\mathrm{B} 3$ is 0.23 and $\mathrm{B} 5$ is 0.22 and $\mathrm{B} 1$ is 0.21 and $\mathrm{B} 2$ is 0.19 and $\mathrm{B} 4$ is 0.17 . The values of $\mathrm{SD}$ are minimum at $\mathrm{B} 2$ and maximum at B5. A detailed discussion of the monthly of the Angstrom Turbidity (AT) at different bands B1, B2, B3, B4and B5 corresponding by standard deviation of all bands as shown in Table 3c. With respect to AT, the higher values of $\mathrm{AT}$, at $\mathrm{B} 3$ is $0.12, \mathrm{~B} 4$ and $\mathrm{B} 1$ are 0.11 and $\mathrm{B} 2$ is 0.10 and $\mathrm{B} 4$ is 0.09 . The mean values of $\mathrm{SD}$ are the same at 0.04 . A detailed discussion of the monthly of the Linke Turbidity (LT) at different bands B1, B2, B3, B4and B5 corresponding by standard deviation of all bands as shown in Table $3 \mathrm{~d}$. With respect to $\mathrm{LT}$, the higher values of $\mathrm{LT}$ at $\mathrm{B} 3$ are 5.81 and $\mathrm{B} 5$ is $5.61, \mathrm{~B} 1$ is 5.30 and $\mathrm{B} 2$ is 4.85 and $\mathrm{B} 4$ is 4.22 . The values of $\mathrm{SD}$ have changed from minimum at $\mathrm{B} 2$ around 0.47 to maximum at B5 around 0.77. Generally, the higher turbidity lies in the B3 $(530-630 \mathrm{~nm})$ and higher changed in SD is clear in the B5 $(695-2800 \mathrm{~nm})$. Figure 1-4 shows the AOD, ST, AT, LT in different bands from $\mathrm{B} 1, . ., \mathrm{B} 5$ which clear that the values of $\mathrm{B} 3$ is the higher values for the other bands. From the previous discussion and from Table $3 \mathrm{a}$, it is notice that, the values of the different turbidity in the after noon are higher than before noon, where the optical depth is large as the results to increases of temperature, which reached the maximum by $2 \mathrm{~h}$ after true noon and then the expansion of atmosphere depth. Figure 5-9 shows the AOD, $\alpha, \mathrm{ST}, \mathrm{AT}$, LT corresponding air mass, where the higher values of turbidity lies at the minimum values of air masses around true noon. However, the increases values that occur after air mass 4 indicate to the theoretical failed of the estimation of air masses. 
Am. J. Applied Sci., 7 (5): 647-655, 2010

Table 3: (a) Estimation of Aerosol Optical Depth (AOD), (b) Schuepp Turbidity (ST), (c) Angstrom Turbidity (AT ), (d) Linke Turbidity (LT ) at different bands B1, B2, B3, B4 and B5 coincident by Standard Deviation (SD) of all bands

\begin{tabular}{|c|c|c|c|c|c|c|c|c|c|c|c|c|c|c|}
\hline \multirow{2}{*}{\multicolumn{3}{|c|}{$\begin{array}{l}\text { Bands Jan. } \\
\text { (a) Aerosol optical depth }\end{array}$}} & Feb. & Mar. & Apr. & May & Jun. & Jul. & Aug. & Sep. & Oct. & Nov. & Dec. & Mean \\
\hline & & & & & & & & & & & & & & \\
\hline \multirow[t]{2}{*}{$\mathrm{B} 1$} & Mean & 0.38 & 0.42 & 0.34 & 0.54 & 0.60 & 0.61 & 0.59 & 0.57 & 0.52 & 0.46 & 0.40 & 0.42 & 0.50 \\
\hline & S D & 0.07 & 0.08 & 0.09 & 0.07 & 0.05 & 0.07 & 0.07 & 0.07 & 0.07 & 0.07 & 0.08 & 0.09 & 0.07 \\
\hline \multirow[t]{2}{*}{ B2 } & Mean & 0.37 & 0.39 & 0.28 & 0.49 & 0.50 & 0.51 & 0.48 & 0.51 & 0.47 & 0.42 & 0.40 & 0.45 & 0.44 \\
\hline & S D & 0.04 & 0.07 & 0.05 & 0.06 & 0.05 & 0.04 & 0.03 & 0.04 & 0.05 & 0.04 & 0.07 & 0.09 & 0.05 \\
\hline \multirow[t]{2}{*}{ B3 } & Mean & 0.40 & 0.43 & 0.42 & 0.63 & 0.64 & 0.69 & 0.67 & 0.60 & 0.55 & 0.50 & 0.43 & 0.47 & 0.55 \\
\hline & S D & 0.08 & 0.09 & 0.10 & 0.09 & 0.04 & 0.07 & 0.07 & 0.07 & 0.06 & 0.08 & 0.07 & 0.10 & 0.07 \\
\hline \multirow[t]{2}{*}{ B4 } & Mean & 0.32 & 0.35 & 0.33 & 0.47 & 0.48 & 0.48 & 0.42 & 0.43 & 0.45 & 0.36 & 0.34 & 0.35 & 0.40 \\
\hline & S D & 0.05 & 0.09 & 0.07 & 0.07 & 0.03 & 0.06 & 0.06 & 0.06 & 0.11 & 0.05 & 0.08 & 0.09 & 0.07 \\
\hline \multirow[t]{2}{*}{ B5 } & Mean & 0.35 & 0.43 & 0.36 & 0.58 & 0.65 & 0.68 & 0.66 & 0.62 & 0.56 & 0.50 & 0.40 & 0.41 & 0.54 \\
\hline & S D & 0.09 & 0.09 & 0.10 & 0.08 & 0.08 & 0.10 & 0.09 & 0.09 & 0.10 & 0.11 & 0.10 & 0.11 & 0.09 \\
\hline \multicolumn{15}{|c|}{ (b) Schuepp turbidity } \\
\hline \multirow[t]{2}{*}{ B1 } & Mean & 0.16 & 0.18 & 0.15 & 0.23 & 0.26 & 0.27 & 0.26 & 0.25 & 0.22 & 0.20 & 0.17 & 0.18 & 0.21 \\
\hline & S D & 0.03 & 0.04 & 0.04 & 0.03 & 0.02 & 0.03 & 0.03 & 0.03 & 0.03 & 0.03 & 0.03 & 0.05 & 0.03 \\
\hline \multirow[t]{2}{*}{ B2 } & Mean & 0.16 & 0.17 & 0.12 & 0.21 & 0.23 & 0.22 & 0.21 & 0.22 & 0.21 & 0.18 & 0.17 & 0.20 & 0.19 \\
\hline & S D & 0.02 & 0.03 & 0.02 & 0.02 & 0.02 & 0.02 & 0.01 & 0.02 & 0.02 & 0.02 & 0.03 & 0.04 & 0.02 \\
\hline \multirow[t]{2}{*}{ B3 } & Mean & 0.19 & 0.18 & 0.18 & 0.28 & 0.28 & 0.30 & 0.29 & 0.26 & 0.24 & 0.22 & 0.17 & 0.21 & 0.23 \\
\hline & S D & 0.03 & 0.04 & 0.04 & 0.04 & 0.02 & 0.03 & 0.03 & 0.03 & 0.03 & 0.03 & 0.03 & 0.04 & 0.03 \\
\hline \multirow[t]{2}{*}{ B4 } & Mean & 0.14 & 0.15 & 0.10 & 0.21 & 0.21 & 0.19 & 0.18 & 0.18 & 0.19 & 0.16 & 0.14 & 0.15 & 0.17 \\
\hline & S D & 0.02 & 0.04 & 0.03 & 0.03 & 0.02 & 0.02 & 0.03 & 0.02 & 0.06 & 0.02 & 0.03 & 0.04 & 0.03 \\
\hline \multirow[t]{2}{*}{ B5 } & Mean & 0.16 & 0.19 & 0.15 & 0.25 & 0.28 & 0.29 & 0.29 & 0.27 & 0.24 & 0.22 & 0.17 & 0.18 & 0.22 \\
\hline & S D & 0.04 & 0.04 & 0.05 & 0.04 & 0.03 & 0.04 & 0.04 & 0.04 & 0.04 & 0.05 & 0.04 & 0.05 & 0.04 \\
\hline \multicolumn{15}{|c|}{ (c) Angstrom turbidity } \\
\hline \multirow[t]{2}{*}{ B1 } & Mean & 0.11 & 0.13 & 0.06 & 0.13 & 0.14 & 0.07 & 0.07 & 0.10 & 0.13 & 0.11 & 0.12 & 0.12 & 0.11 \\
\hline & S D & 0.02 & 0.04 & 0.07 & 0.05 & 0.03 & 0.02 & 0.02 & 0.04 & 0.04 & 0.04 & 0.05 & 0.04 & 0.04 \\
\hline \multirow[t]{2}{*}{ B2 } & Mean & 0.11 & 0.12 & 0.06 & 0.11 & 0.13 & 0.06 & 0.06 & 0.09 & 0.12 & 0.10 & 0.12 & 0.13 & 0.10 \\
\hline & S D & 0.02 & 0.04 & 0.06 & 0.04 & 0.02 & 0.02 & 0.02 & 0.04 & 0.04 & 0.04 & 0.05 & 0.05 & 0.04 \\
\hline \multirow[t]{2}{*}{ B3 } & Mean & 0.12 & 0.13 & 0.08 & 0.15 & 0.15 & 0.08 & 0.08 & 0.10 & 0.13 & 0.12 & 0.12 & 0.13 & 0.12 \\
\hline & S D & 0.02 & 0.05 & 0.08 & 0.06 & 0.03 & 0.02 & 0.03 & 0.04 & 0.04 & 0.04 & 0.05 & 0.04 & 0.04 \\
\hline \multirow[t]{2}{*}{ B4 } & Mean & 0.09 & 0.11 & 0.05 & 0.11 & 0.11 & 0.05 & 0.05 & 0.07 & 0.11 & 0.09 & 0.10 & 0.10 & 0.09 \\
\hline & S D & 0.02 & 0.05 & 0.08 & 0.05 & 0.03 & 0.02 & 0.01 & 0.03 & 0.06 & 0.03 & 0.05 & 0.04 & 0.04 \\
\hline \multirow{2}{*}{ B5 } & Mean & 0.11 & 0.13 & 0.07 & 0.14 & 0.15 & 0.08 & 0.08 & 0.11 & 0.14 & 0.12 & 0.12 & 0.12 & 0.11 \\
\hline & S D & 0.02 & 0.05 & 0.07 & 0.07 & 0.04 & 0.02 & 0.02 & 0.04 & 0.04 & 0.05 & 0.05 & 0.05 & 0.04 \\
\hline \multicolumn{15}{|c|}{ (d) Linke turbidity } \\
\hline Bands & & Jan. & Feb. & Mar. & Apr. & May & Jun. & Jul. & Aug. & Sep. & Oct. & Nov. & Dec. & Mean \\
\hline B1 & Mean & 3.99 & 4.26 & 3.72 & 5.63 & 6.45 & 6.80 & 6.70 & 6.31 & 5.69 & 5.06 & 4.34 & 4.63 & 5.30 \\
\hline & S D & 0.41 & 0.64 & 0.75 & 0.52 & 0.40 & 0.57 & 0.59 & 0.54 & 0.53 & 0.56 & 0.62 & 0.88 & 0.58 \\
\hline B2 & Mean & 3.90 & 3.99 & 3.08 & 5.16 & 5.82 & 5.74 & 5.60 & 5.74 & 5.24 & 4.56 & 4.37 & 4.99 & 4.85 \\
\hline & S D & 0.20 & 0.65 & 0.39 & 0.57 & 0.47 & 0.42 & 0.24 & 0.41 & 0.51 & 0.40 & 0.63 & 0.75 & 0.47 \\
\hline B3 & Mean & 4.66 & 4.37 & 4.61 & 6.61 & 6.89 & 7.58 & 7.53 & 6.64 & 6.03 & 5.51 & 4.36 & 5.26 & 5.84 \\
\hline & S D & 0.53 & 0.71 & 0.79 & 0.74 & 0.37 & 0.56 & 0.57 & 0.61 & 0.50 & 0.61 & 0.61 & 0.79 & 0.61 \\
\hline B4 & Mean & 3.42 & 3.49 & 2.49 & 4.92 & 5.26 & 5.05 & 4.91 & 4.84 & 4.99 & 3.93 & 3.49 & 3.85 & 4.22 \\
\hline & S D & 0.35 & 0.85 & 0.85 & 0.58 & 0.25 & 0.56 & 0.60 & 0.53 & 1.52 & 0.49 & 0.75 & 0.80 & 0.68 \\
\hline B5 & Mean & 4.00 & 4.43 & 3.81 & 5.99 & 6.93 & 7.48 & 7.45 & 6.81 & 6.11 & 5.48 & 4.39 & 4.46 & 5.61 \\
\hline & S D & 0.62 & 0.69 & 0.88 & 0.64 & 0.60 & 0.83 & 0.82 & 0.74 & 0.81 & 0.90 & 0.78 & 0.98 & 0.77 \\
\hline
\end{tabular}

Note: B1: 280-2800 nm; B2: 280-530 nm; B3: 530-630 nm; B4: 630-695 nm; B5: 695-2800 nm

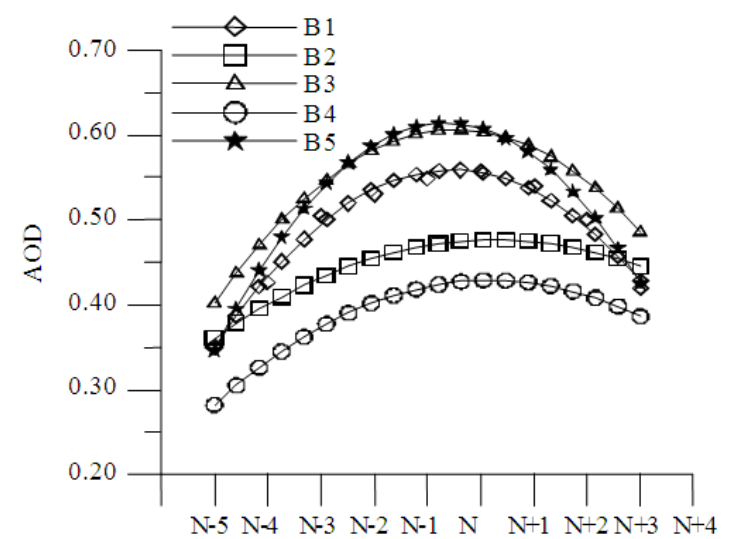

Fig. 1: Variation of Aerosol Optical Depth (AOD) with air masses for B1,...B5

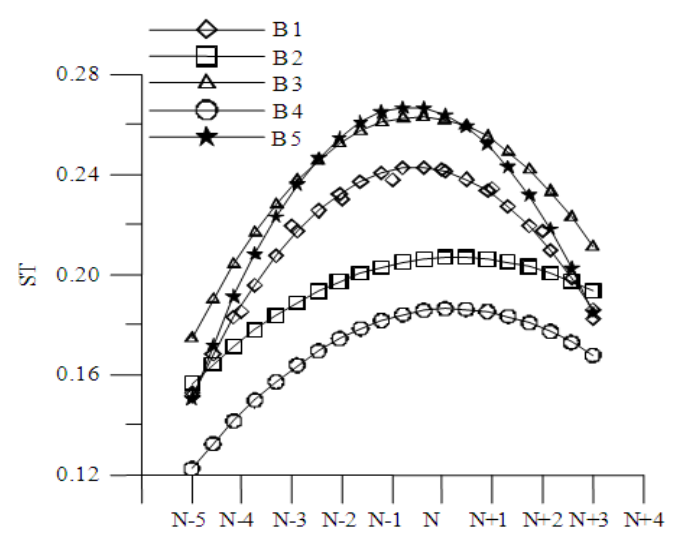

Fig. 2: Variation of Schuepp Turbidity (ST) with air masses for B1,...B5 


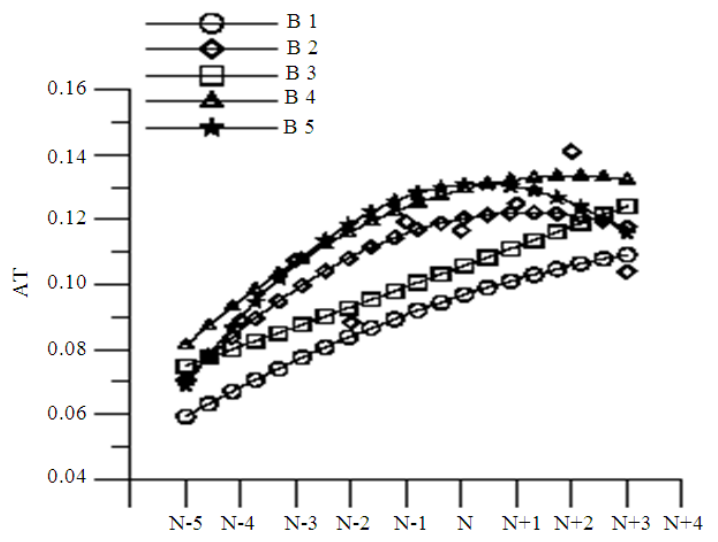

Fig. 3: Variation of Angstrom Turbidity (AT) with air masses for $\mathrm{B} 1, \ldots \mathrm{B} 5$

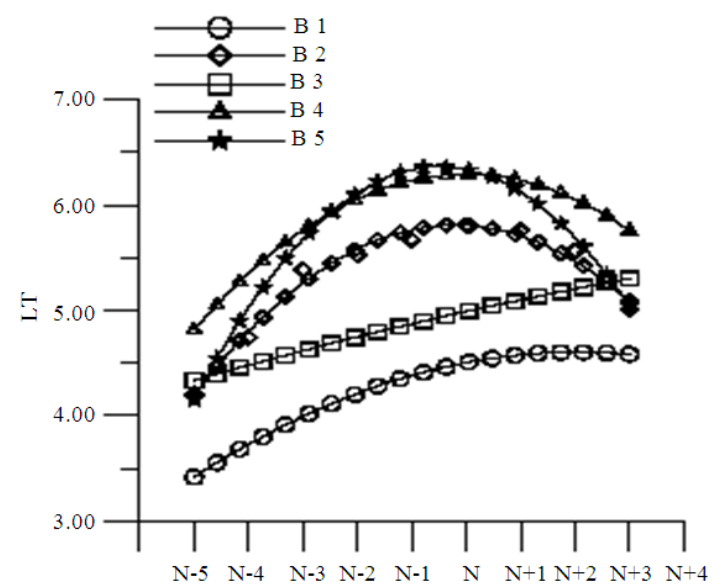

Fig. 4: Variation of Linke Turbidity (LT) with air masses for B1,...B5

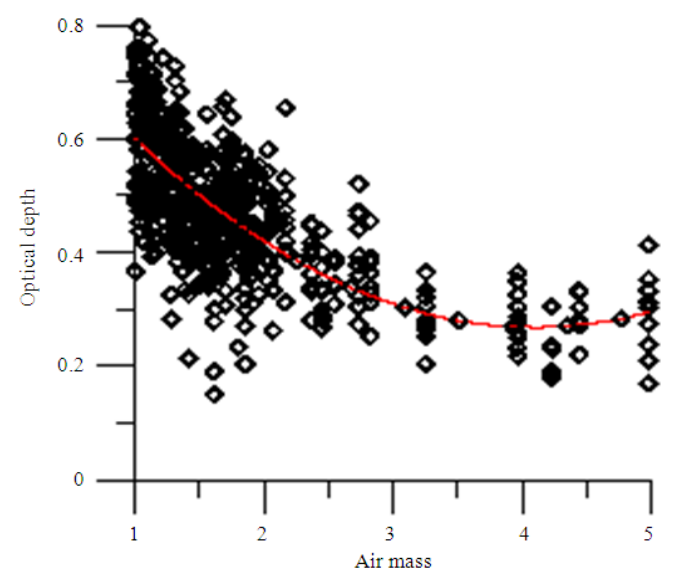

Fig. 5: Variation of Aerosol Optical Depth (AOD) corresponding to air masses

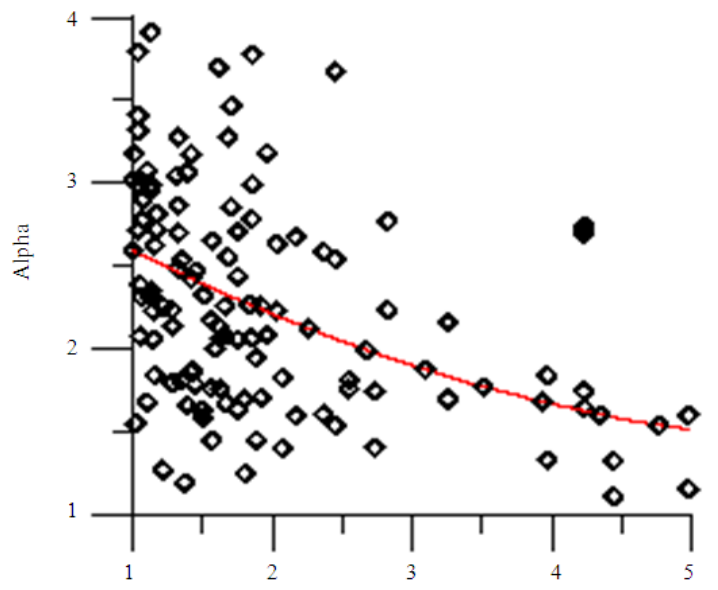

Air mass

Fig. 6: Variation of Alpha corresponding to air masses

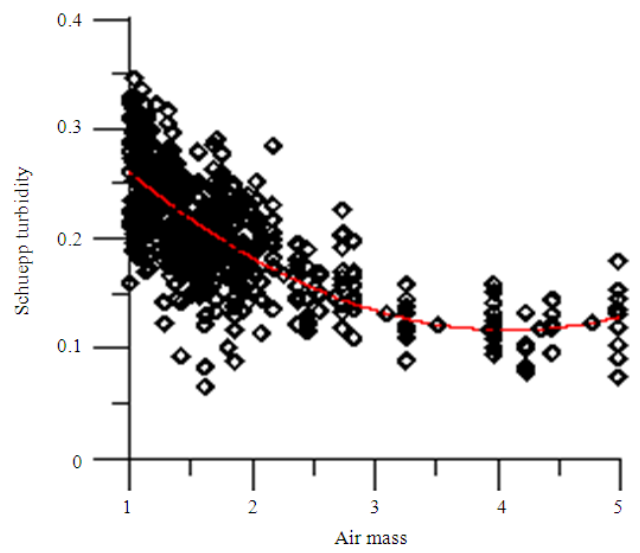

Fig. 7: Variation of Schuepp Turbidity corresponding to air masses

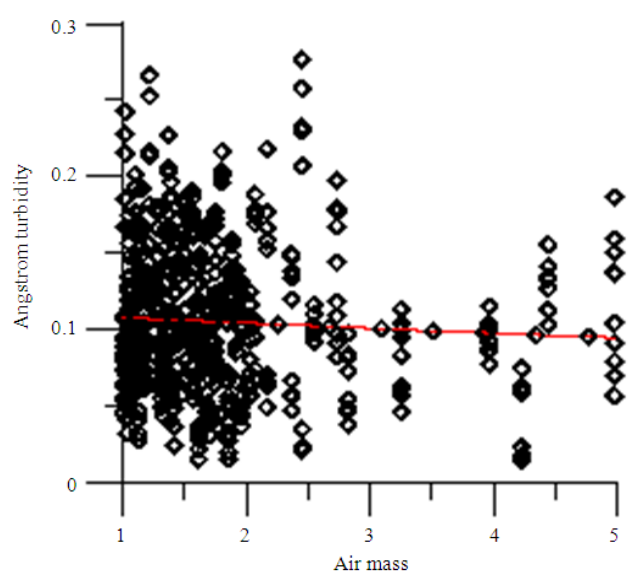

Fig. 8: Variation of Angstrom Turbidity (AT) corresponding to air masses 
Am. J. Applied Sci., 7 (5): 647-655, 2010

Table 4: Different values of $\alpha$ can have derived from Eq. 9

\begin{tabular}{|c|c|c|c|c|c|c|c|c|c|c|c|c|}
\hline & Jan. & Feb. & Mar. & Apr. & May & Jun. & Jul. & Aug. & Sep. & Oct. & Nov. & Dec. \\
\hline \multicolumn{13}{|c|}{ Before noon } \\
\hline $\mathrm{N}-4$ & 1.32 & 2.16 & 1.64 & 3.18 & 2.05 & 3.27 & 3.46 & 2.78 & 2.67 & 2.77 & 1.33 & 1.60 \\
\hline $\mathrm{N}-3$ & 1.81 & 1.82 & 3.67 & 2.47 & 1.80 & 3.05 & 2.86 & 3.06 & 2.17 & 1.45 & 2.58 & 1.74 \\
\hline $\mathrm{N}-2$ & 2.26 & 2.06 & 3.78 & 1.27 & 2.23 & 3.91 & 2.35 & 2.81 & 2.14 & 1.58 & 1.69 & 2.63 \\
\hline $\mathrm{N}-1$ & 2.26 & 1.85 & 3.70 & 1.68 & 2.39 & 3.79 & 3.41 & 2.90 & 2.62 & 2.48 & 2.65 & 2.70 \\
\hline \multicolumn{13}{|c|}{ At noon } \\
\hline $\mathrm{N}$ & 2.00 & 1.19 & 3.18 & 2.31 & 1.55 & 3.02 & 3.18 & 2.71 & 2.31 & 2.23 & 2.32 & 1.67 \\
\hline \multicolumn{13}{|c|}{ After noon } \\
\hline $\mathrm{N}+1$ & 2.08 & 1.88 & 2.14 & 3.07 & 2.07 & 2.99 & 3.32 & 2.78 & 1.84 & 2.70 & 1.45 & 1.63 \\
\hline $\mathrm{N}+2$ & 1.71 & 1.76 & 2.99 & 2.26 & 2.05 & 2.96 & 2.99 & 2.72 & 1.79 & 1.63 & 1.24 & 2.23 \\
\hline $\mathrm{N}+3$ & 1.76 & 1.40 & 0.54 & 1.78 & 2.54 & 3.04 & 3.27 & 1.66 & 1.76 & 1.94 & 1.60 & 1.40 \\
\hline $\mathrm{N}+4$ & 1.31 & 1.70 & 3.74 & 2.08 & 2.44 & 2.55 & 2.85 & 2.06 & 1.59 & 2.23 & 1.84 & 1.15 \\
\hline Mean & 1.81 & 1.76 & 2.81 & 2.23 & 2.13 & 3.18 & 3.08 & 2.61 & 2.10 & 2.11 & 1.86 & 1.86 \\
\hline SD & 0.31 & 0.32 & 0.61 & 0.63 & 0.39 & 0.43 & 0.35 & 0.45 & 0.38 & 0.49 & 0.53 & 0.54 \\
\hline
\end{tabular}

Table 5: Linear relationships between different parameter AOD, $\alpha$, ST, AT and LT at Helwan

\begin{tabular}{llllllll}
\hline AOD & $\alpha$ & ST & AT & LT & a & b & R \\
\hline$*$ & & $* *$ & & & 0.001 & 0.434 & 0.99 \\
$*$ & $* *$ & & & & 1.660 & 1.336 & 0.68 \\
$*$ & & & $* *$ & & 0.050 & 0.106 & 0.87 \\
$*$ & & & & $* *$ & 0.261 & 10.33 & 0.95 \\
& $* *$ & $*$ & & & 1.665 & 3.077 & 0.67 \\
& & $*$ & $* *$ & & 0.056 & 0.245 & 0.87 \\
& & $*$ & & $* *$ & 0.262 & 23.79 & 0.95 \\
& $*$ & & $* *$ & & 0.228 & -0.053 & 0.67 \\
& $*$ & & & $* *$ & 3.761 & 0.606 & 0.66 \\
& & & $*$ & $* *$ & 4.405 & 7.169 & 0.89 \\
\hline
\end{tabular}

$\mathrm{Y}=\mathrm{a}+\mathrm{b} \mathrm{X}$; **: Y-Axis; *: X-Axis; a, b: Variable Coefficient; R: Coefficient of determination

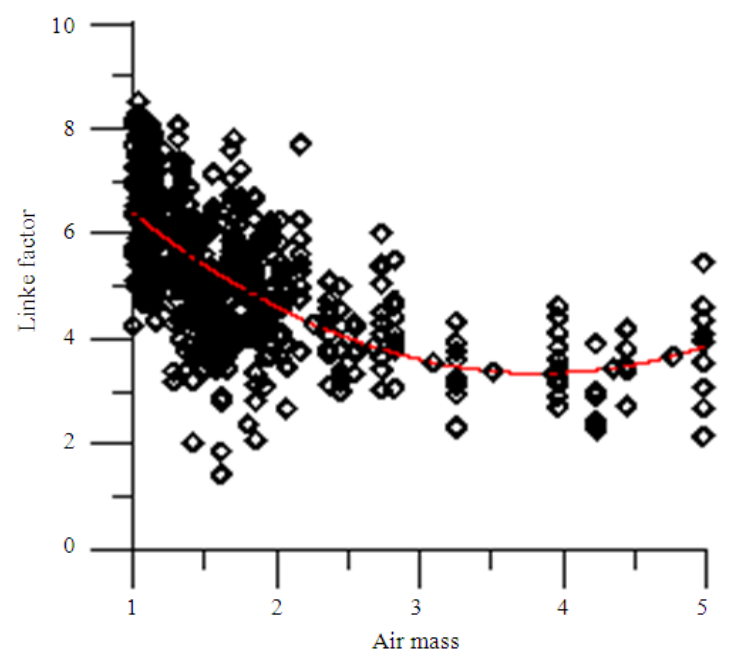

Fig. 9: Variation of Linke Turbidity corresponding to air masses

Table 4 shows, the variation of $\alpha$ parameter which derived from the equation 9. The values indicated to change in the values of $\alpha$ from 1.81 in January until reach to maximum values in June at 3.18 and decrease another time until reach to December. The values of the
SD indicate to the higher values in the March is 0.61 and April is 0.63 causing the Khamasien storm, which pass at Egypt in this months and increase of little influence of relative humidity on aerosol size and optical properties and minimum at January and February is $0.31-0.32$. Table 5 represents the linear relationships between different turbidity parameters $\mathrm{AOD}, \alpha, \mathrm{ST}$, AT and LT, where the higher relation between AOD and ST is 0.99, AOD and LT is 0.95and minimum relation between $\alpha$ and other parameters.

\section{DISCUSSION}

The AOD distribution has a significant seasonal change as the indicated by strong seasonal variation in Table 4. Angstrom wavelength exponent values average 1.3-3.18 for non-burning season months, while for the peak burning season months of April-May, the average of AOD is $0.63-0.64$, due to Khamasien storm. This may explain in part why the values of AOD from cement factories are so similar in such widely differing environments as Helwan, thussuggesting differing aerosol types on different days. Although the seasonal and inter-annual variation of AOD has dominated by biomass burning aerosols from forest fires, there are additional sources of aerosol, which are present also. These values result from accumulation mode dominated smoke aerosols with typical log normal volume size distribution radius values lies highly effect at B3 which, wavelength ranged $530-630 \mathrm{~nm}$ for the accumulation mode. The range in four cement factories aerosols is dependent in part on the type of fuels burned, the type of combustion (flaming or smoldering) and the aging processes of the aerosol as it is transported. In July, the dominant component is cement, with substantial contributions from dust. In October, cloud is again the most dominant contributor but dust is also important. Since the wavelengths dependence of extinction by 
water vapor and dust are different from the wavelength dependence of extinction by pure air, the turbidity factor varies diurnally. Even when the amount of water vapor and dust are constant, i.e., Linke's Turbidity factor (LT) depends on the relative optical air mass $\mathrm{m}_{\mathrm{r}}$, attribute the dependence of Linke's turbidity factor on relative optical air mass for two reasons. Firstly, Linke's turbidity factor has related to the aerosol and water vapor transmittances integrated over the solar spectrum. Secondly, Linke's turbidity factor depends on the optical thickness of the clean dry atmosphere that is very sensitive to the relative optical air mass $m_{r}$. The result is a virtual increase of Linke's turbidity factor with solar elevation. In addition, a real seasonal variation of $\mathrm{LT}$ is $\mathrm{m}$ observed in our location, with maximum in summer (June, July, August) afternoon hours and minimum in winter (December, January, February) morning hours. Also the spring values of LT are closer to summer values and $m$ autumn values of $L T$ closer to winter ones. In our $\mathrm{m}$ case, high LT has observed in September. There are main characteristics concerning the climate of Helwan that effect of the solar radiation. Cloud characteristic and atmospheric Transparency change markedly from one season to another as follows:

- Spring is characterized by passage of small and shallow thermal disturbance, inducing what is called "Khamasien weather", with the onset of such thermal lows, vertical visibility deteriorates progressively with raising cluster content in the lower layers of the atmosphere. Occasionally, stratified cloud types that proceed from high transparent cirrus type to medium opaque alto and nimbostratus cloud accompany this. After the passage of the disturbance, cumuliform clouds and low turbidity prevail

- Summer, high transparent and semi-transparent clouds prevail, when they exit and the sky is "dirty" most of time, thanks to a deep layer of fine dust particles associated with continental tropical air. The dust content falls markedly when Mediterranean air arrives, with associated fine weather cumulus

- During autumn, the atmosphere is generally moderately transparent and the morning mists and low clouds formed tend to dissipate after sunrise. The weather regime is very steady

- Winter is characterized by prevail conditions of middle-latitude disturbances, where clouds are normally opaque to the direct beam and the turbidity of the atmosphere is low. There is a marked variation in climate from north to south.
Thus, the north coastal strip, several kilometers wide, does not by the above-described succession of seasonal regime in a clear-cut manner; cover and frequency prevail over the year. Clean air is a rule and dust-laden air is only an exception. The continental tropical patters manifest themselves southward more and more. Going further to south, the extra tropical regimes do not show except in mid winter

\section{CONCLUSION}

The atmospheric area under studied and at the same air masses are characteristic as:

- The AOD decreases with decreasing relative optical air mass. This fact is due to the wavelength dependence of the extinction parameter of the solar radiation by the atmospheric constituents

- The minimum of AOD is in the afternoon at summer, while the maximum is in the before noon at winter

- The diffuse radiation presents diurnal and annual variations are a maximum in the afternoon at summer and a minimum in the morning at winter. The diffuse radiation intensity increases with solar elevation and with atmospheric turbidity depending on air mass origin

- The annual variation of turbidity has estimated to be about $40 \%$, between the morning value of turbidity in February and the afternoon value in June. The summer maximum of atmospheric turbidity has attributed to the summer maximum of the air specific humidity and dust content

- The origin of the air masses has major weight on the annual atmospheric turbidity variation. The Khmasien combined with the continental dust, carried by east-northeastern winds over the location, giving rise to high turbidity levels. During the winter, strong east-northeastern winds carry clean, dust free and dry continental air masses

- Regression best-fit lines of atmospheric turbidity with specific humidity and of diffuse radiation intensity with atmospheric turbidity show the major role of continental aerosol in air pollution and radiation scattering physical processes

- The results clearly show seasonal dynamics in aerosol loading, type and perceptible water. Background levels of aerosols, which we define as yellow color (B3) less than 0.10, has observed at almost all sites but varying frequencies.

\section{REFERENCES}

Andreae, M.O., 1996. Raising dust in the greenhouse. Nature, 380: 389-390. 
Angstrom, A., 1996. Techniques of determining the turbidity of the atmosphere. Tellus, 13: 214-223.

Ben Mohamed, A., J.P. Frangi, J. Fontan and A. Druilhet, 1992. Spatial and temporal variations of atmospheric turbidity and related parameters in Niger. J. Applied Met., 31: 1286-1294.

D’Almeida, G.A., 1996. A model for Saharan dust transport. J. Clim. Applied Meteor., 25: 903-916.

Dutton, E.G., P. Reddy, S. Ryan and J.J. DeLuisi, 1994. Features and effects of aerosol optical depth observed at Mauna Loa, Hawaii: 1982-1992. J. Geophys. Res., 99: 8295-8306.

Eck, T.F., B.N. Holben, J.S. Reid, O. Dubovik and A. Smirnov et al., 1999. The wavelength dependence of the optical depth of biomass burning, urban and desert dust aerosols. J. Geophys. Res., 104: 31,333-31,349.

Elminir, H.K., U.A. Rahoma and A.B. Abdel-Aziz, 2004. On the relationship between anthropogenic air pollutants and solar ultravilolet radiation in the city of Cairo. Nat. Res. Inst. Ast. Geophys. J. Nov, 55: 59-67.

Forgan, B.W., J.J. DeLuisi, B.B. Hicks and E.N. Rusina, 1993. Report on the measurements of atmospheric turbidity in BAPMoN. WMO Rep. Geneva, 94: 65-71.

Hassan, A.H., 2001. The variability of the daily solar radiation, components over Helwan. Renewable Energy, 23: 641-649.

Intergovernmental Panel on Climate Change, (IPCC) 1994. Radiative Forcing of Climate 1994, Report to IPCC from the Scientific Assessment Working Group (WGI).

Jinhuan, Q. and Y. Liquan, 2000. Variation characteristics of atmospheric aerosol optical depths and visibility in North China during 19801994. Atmosph. Environ., 34: 603-609.

Katez, M., A. Baille and M. Mermier, 1982. Atmospheric turbidity in a semi rural site $\mathrm{I}$. Evaluation and comparison of different atmospheric turbidity coefficient. Solar Energy, 28: 323-327.
King, M.D., Y.J. Kaufman, D. Tanre and T. Nakajima, 1999. Remote sensing of tropospheric aerosols from space: Past present and future. Bull. Am. Meteor. Soc., 80: 2229-2259.

Mattar, T. and U.A. Rahoma, 2002. Environmental pollution effect of ferro-manganese industry on solar spectrum. J. Mater. Sci. Technol., 10: 35-44.

Mosalam Shaltout, M.A., A.H. Hassan and A.M. Fathy, 2001. Total suspended particles and solar radiation over Cairo and Aswan. Renew. Energy, 23: 605-619.

Mosalam Shaltout, M.A. and U.A. Rahoma, 1996. Atmospheric turbidity parameters in the high polluted site of Egypt. Proceedings of the 5th International Conference on Energy and Environment, June3-6, Cairo, Egypt, pp: 659-675.

Mosalam Shaltout, M.A., A.H. Hassan and U.A. Rahoma, 1998. Measurements of suspended particles and aerosols in atmosphere of Helwan, Egypt. Proceedings of the 6th International Conference on Energy and Environment Conference, May 18-21, Cairo, Egypt, pp: 467-478.

Pruppacher, H.R. and J.D. Klett, 1978. Microphysics of Clouds and Precipitation. D. Reidel Publication Co., Boston, pp: 714.

Rahoma, U.A., 2001. Clearness index estimation for spectral composition of direct and global solar radiation. Applied Energy, 68: 337-346.

Rahoma, U.A., 2004. Impact of atmospheric aerosol particles on continuous solar spectral distributions. J. Astronomic. Soc. Egypt, 12/I: 26-49.

Schuepp, W., 1949. Estimating of atmospheric turbidity components using measurements of actinometer. Arch. Met. Geophys. Bioklim. B1: 257-617.

Sonntag, K., 1989. Trainingsfoeschung in WorkRelated Learning Psychology Berfsbe with Altered Activity Content. Huber, Bern.

Trabeaa, A.A. and M.A.M. Shaltout, 2000. Correlation of global solar radiation with meteorological parameters over Egypt. Renew. Energy, 21: 297-308. 